\title{
PENGGUNAAN PUPUK KASCING PADA BUDIDAYA SELADA (Lactuca sativa L.) DI KECAMATAN SUKALARANG KABUPATEN SUKABUMI
}

\section{THE USE OF VERMICOMPOST FERTILIZER IN CULTIVATION OF Lettuce (Lactuca sativa L.) IN SUKALARANG SUKABUMI DISTRICT}

\author{
Fitri Rahmi Ramadanti ${ }^{1}$, Tri Ratna Saridewi ${ }^{2}$, Dayat ${ }^{2}$ \\ ${ }^{1}$ Mahasiswa Jurusan Pertanian, Politeknik Pembangunan Pertanian Bogor \\ ${ }^{2}$ Dosen Jurusan Pertanian, Politeknik Pembangunan Pertanian Bogor \\ JI Aria Surialaga No 1 Bogor, Jawa Barat \\ *Korespondensi penulis, Email: fitri.rahmi06@gmail.com
}

Diterima: November 2020

Disetujui terbit: Desember 2020

\begin{abstract}
Vegetable cultivation activities in Sukalarang Subdistrict, Sukabumi Regency use organic fertilizer to improve the quality of agricultural production by giving attention to sustainable agriculture. Chicken manure is widely used by farmers, while vermicompost fertilizer is still not used. Vermicompost fertilizer is the use of cow manure waste as media for worm cultivation of vermicomposting process. Developing vermicompost fertilizer is quite good because there are a lot of cattle breeders in that location. One of the efforts to motivate farmers to use vermicompost is create a pilot plot as a source of information for lettuce farmers. The method of analysis used the $T$ test to see the significance of using vermicompost fertilizer and chicken manure. Observations were made on plant height and number of leaves on a weekly basis and calculated the production value of both treatments. The results showed that plant height, number of leaves and yield from both treatments were not significantly different. These results indicate that the use of vermicompost fertilizer can be an alternative to replace the use of chicken manure.
\end{abstract}

Keywords: Vermicompost, fertilizer use, lettuce

\begin{abstract}
ABSTRAK
Kegiatan budidaya sayuran di Kecamatan Sukalarang Kabupaten Sukabumi memanfaatkan pupuk organik untuk meningkatkan kualitas produksi hasil pertanian dengan memperhatikan pertanian berkelanjutan. Pupuk kotoran ayam banyak digunakan petani, sedangkan pupuk kascing masih belum digunakan. Pupuk kascing merupakan pemanfaatan limbah kotoran sapi sebagai media budidaya cacing dari proses vermikomposting. Potensi pengembangan pupuk kascing cukup besar karena peternak sapi di lokasi tersebut cukup banyak. Salah satu upaya yang dilakukan untuk memotivasi petani dalam menggunakan kascing adalah dengan membuat petak percontohan sebagai sumber informasi bagi petani selada. Metode analisis menggunakan uji $\mathrm{T}$ untuk melihat signifikansi penggunaan pupuk kascing dengan pupuk kotoran ayam yang biasa petani gunakan. Pengamatan dilakukan terhadap tinggi tanaman dan jumlah daun secara mingguan dan menghitung nilai produksi dari kedua perlakuan. Hasil menunjukkan bahwa tinggi tanaman, jumlah daun dan hasil produksi dari penggunaan pupuk kascing dan pupuk kotoran ayam tidak berbeda nyata. Hasil tersebut menunjukkan bahwa penggunaan pupuk kascing dapat menjadi alternatif untuk menggantikan penggunaan pupuk kotoran ayam.

Kata Kunci: kascing, penggunaan pupuk, selada
\end{abstract}




\section{PENDAHULUAN}

\section{Latar Belakang}

Sayuran merupakan tanaman yang memiliki nilai gizi yang tinggi, di antaranya vitamin, serat, kalsium, besi, karoten dan kandungan lainnya. Sayuran dapat meningkatkan metabolisme tubuh untuk kesehatan (Nugroho et al., 2017). Produktivitas sayuran di Indonesia per tahun mencapai di atas 2,5 juta ton, penyumbang produksi sayuran terbesar terdapat di Jawa Barat (BPS, 2014). Salah satunya di Kecamatan Sukalarang, Kabupaten Sukabumi, terdapat desa yang dijadikan sebagai desa sentra sayuran yaitu Desa Sukamaju.

Kecamatan

Sukalarang

melaksanakan pemanfaatan dan pelestarian sumber daya alam, serta peningkatan produksi kualitas hasil pertanian sebagai bentuk dukungan menuju pertanian secara berkelanjutan, melalui penggunaan pupuk organik. Berdasarkan Programa Kecamatan Sukalarang Tahun 2019 yaitu meningkatkan penggunaan pupuk organik pada kegiatan budidaya. Penggunaan pupuk organik di Kecamatan Sukalarang pada budidaya sayuran hanya sebagai pupuk dasar.
Pupuk kotoran ayam termasuk pupuk organik yang sudah digunakan banyak petani, sedangkan untuk pupuk kascing petani masih belum menggunakan. Pupuk organik kotoran ayam maupun kascing memiliki kandungan yang dapat memenuhi kebutuhan tanaman. Pupuk kascing merupakan pupuk yang menurut petani Kecamatan Sukalarang suatu inovasi yang baru mereka tahu. Peternak sapi di Kecamatan Sukalarang cukup banyak, kemudian limbah kotoran sapi banyak terbengkalai dan belum dimanfaatkan petani, karena pengolahan limbah kotoran sapi jika diolah menjadi pupuk kandang sapi harus melalui proses yang cukup lama. Pembuatan pupuk kascing merupakan salah satu inovasi untuk melakukan pemanfaatan limbah kotoran sapi dengan proses yang mudah. Kascing kepanjangan dari bekas cacing diperoleh dari ternak cacing yaitu mendapatkan cacing dan sisa media cacing dari proses vermikomposting. Berkaitan dengan rendahnya penggunaan pupuk kascing pada budidaya selada, sebagai salah satu upaya untuk meningkatkan produksi selada di Kecamatan Sukalarang, sehingga diperlukan adanya pemberian motivasi. 
Pemberian motivasi mengenai penggunaan pupuk kascing dilakukannya petak percontohan sebagai media informasi. Sehubungan dengan hal tersebut maka penelitian ini menganalisis penggunaan pupuk kascing pada budidaya selada (Lactuca sativa L.) di Kecamatan Sukalarang Kabupaten Sukabumi.

\section{METODE PELAKSANAAN}

Waktu penelitian dilakukan pada tanggal 10 April-9 Juni 2020. Lahan yang digunakan untuk melaksanakan kegiatan petak percontohan yaitu merupakan lahan pekarangan petani di Desa Sukalarang Kecamatan
Tujuan penelitian adalah untuk menganalisis perbedaan tinggi tanaman, jumlah daun dan hasil produksi dari petak yang menggunakan pupuk kascing dan pupuk kotoran ayam pada budidaya selada (Lactuca sativa L.) di Kecamatan Sukalarang Kabupaten Sukabumi.

Petak percontohan menggunakan dua perlakuan yaitu penggunaan pupuk kotoran ayam yang telah terbiasa digunakan oleh petani dan penggunaan pupuk kascing. Pengaturan petak percontohan dapat dilihat pada Gambar 1.

\section{Sukalarang.}

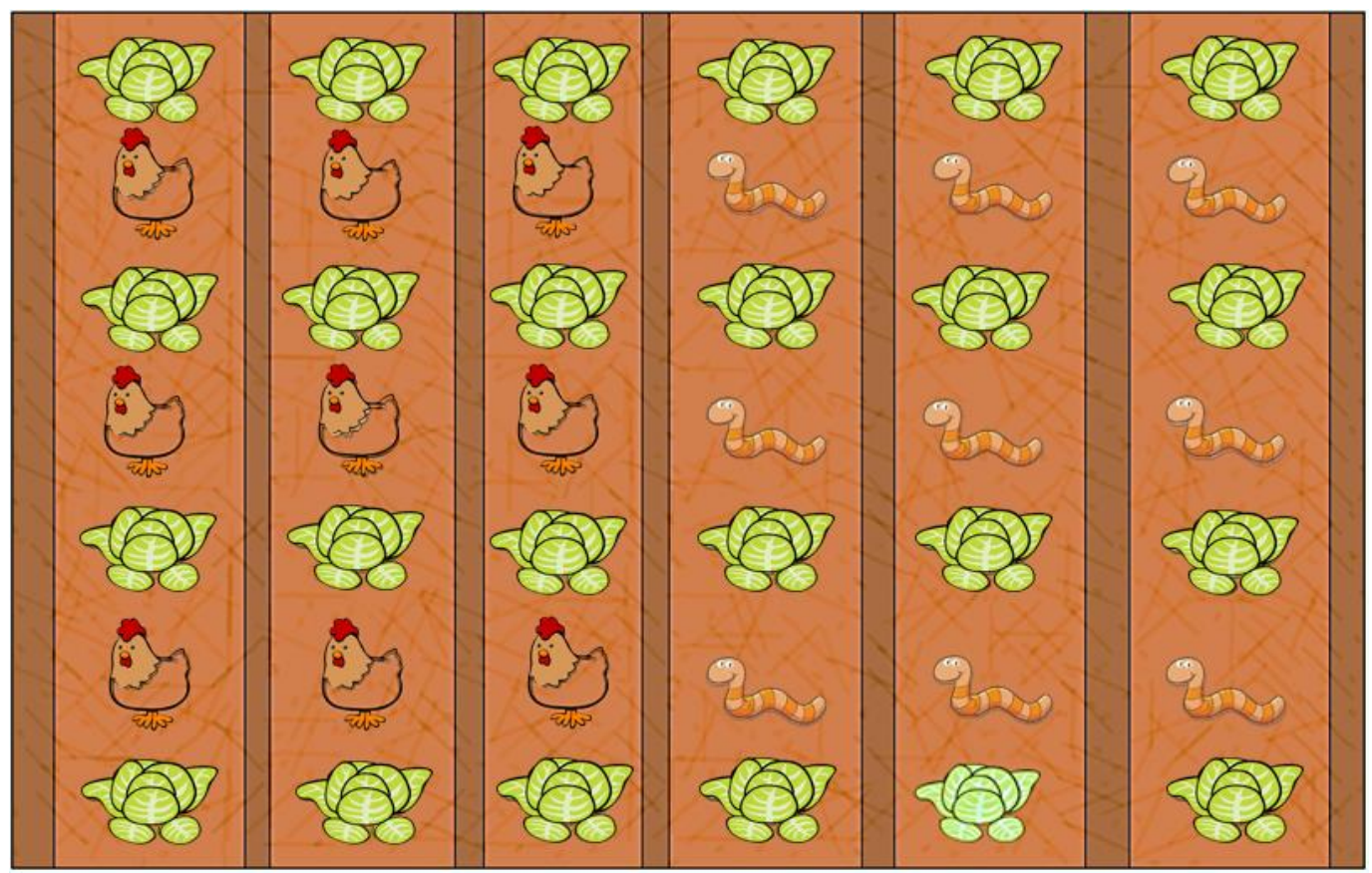

Gambar 1 Petak Percontohan 
Alat dan bahan yang digunakan pada kegiatan petak percontohan merupakan keperluan umum untuk budidaya selada, mulai dari tahap persiapan bibit, kegiatan pembuatan pupuk kascing, kegiatan budidaya dan kegiatan pengamatan yang dilakukan. Alat dan bahan yang digunakan dapat dibagi pada empat jenis kegiatan, antara lain kegiatan persiapan bibit, pembuatan pupuk kascing, kegiatan budidaya, dan pengamatan pertumbuhan tanaman. Alat dan bahan pada kegiatan persiapan bibit antara lain baki semai, benih, tanah, dan pupuk. Alat dan bahan untuk kegiatan pembuatan pupuk kascing antara lain timbangan, keranjang kayu, karung bekas, sekop, ayakan/saringan, cacing, kotoran sapi, tanah, dan air. kegiatan budidaya membutuhkan alat antara lain mulsa, bambu,dan pemotong mulsa. Adapun bahan yang dibutuhkan antara lain pupuk kascing, pupuk kotoran, ayam, dan bibit. Kegiatan pertumbuhan tanaman memerlukan alat dan bahan seperti alat tulis dan sampel tanaman.

Berdasarkan pada pengkajian Nugroho et al. (2017), bahwa pengamatan terhadap penggunaan pupuk dapat melakukan pengamatan dari tinggi daun, jumlah daun dan produktivitasnya.
Rangkaian pelaksanaan kegiatan yaitu:

1) Konsultasi mengenai lahan yang akan digunakan untuk kegiatan petak percontohan.

2) Persiapan lahan, di mana lahan yang digunakan merupakan pekarangan rumah pengkaji. Lahan dipersiapkan dengan membentukan guludan sebanyak 6 bedengan. Petak percontohan yang digunakan dengan 2 percobaan, sehingga terdapat 3 bedengan untuk setiap petak percontohan. Persiapan lahan mulai dari penggarapan lahan menjadi 6 bedengan dan membolongi mulas untuk lubang tanam

3) Pembuatan Pupuk Kascing

$$
\text { Pupuk kascing merupakan }
$$
inovasi baru bagi petani Kecamatan Sukalarang, oleh sebab itu pembuatan pupuk kascing melibatkan petani agar nantinya mampu memproduksi pupuk kascing sesuai kebutuhan. Pembuatan kascing memanfaatkan limbah kotoran sapi yang tidak dimanfaatkan. Adapun tahapan pembuatan pupuk kascing yang dilakukan sebagai berikut:
a) Penyiapan alat dan bahan;
b) Menyiapkan karung sebagai alas keranjang kayu;


c) Memasukkan $1 \mathrm{~kg}$ cacing pada keranjang dan media yang berupa tanah secukupnya atau 1-1,5 kg;

d) Menyimpan kotoran sapi sebanyak $3 \mathrm{~kg}$ di bagian atas tumpukan dalam keranjang kayu sebagai sumber makanan cacing;

e) Pemeliharaan dengan cara penyiraman 7 hari sekali. Apabila kondisi media terlalu kering, dilakukan pemberian air hanya dengan membasahi/menaburkan pada bagian atas saja;

f) Pemeliharaan lainnya yaitu pemeriksaan secara berkala. Pemeriksaan media agar tidak terlalu kering atau basah dan menghindarkan semut atau hewan yang dapat menghambat pengomposan;

g) Pemberian pakan pada cacing menggunakan kotoran sapi dilakukan 1 minggu sekali, dengan melihat kondisi pakan dalam keranjang terlebih dahulu;

h) Setelah 1 bulan, pupuk kascing siap di panen;

i) Memisahkan kascing dengan cacing yang di panen;

j) Agar pupuk yang dihasilkan halus, maka dilakukan penyaringan menggunakan ayakan, guna memisahkan sisa daun kering atau benda lain dari pakan dengan pupuk kascing;

k) Pupuk dikemas dalam karung untuk memudahkan penyimpanan dan pupuk kascing hasil budidaya siap digunakan.

I) Cacing dari hasil budidaya dibagi ke dalam keranjang lain dan budidaya cacing lebih banyak.

4) Pelaksanaan Budidaya

Pelaksanaan

budidaya dilakukan dengan tahapan sebagai berikut:

a) Melakukan kegiatan persemaian bibit yang digunakan dengan media tanam (1:1) tanah dan pupuk. Benih yang digunakan merupakan benih bersertifikat berlabel biru (Grand Rapids);

b) Setelah berumur 8 hari bibit dipindah dari persemaian ke kokeran yang terbuat dari daun hanjuang;

c) Pemberian pupuk dasar menggunakan pupuk berbeda, 3 bedeng dilakukan pemupukan menggunakan pupuk kotoran ayam 5 hari sebelum tanam dan 3 bedeng menggunakan pupuk kascing 1 hari sebelum tanam;

d) Penanaman dilakukan pada bibit umur 3 - 4 minggu dengan 
jumlah daun 4-5 helai. Jarak tanam yang digunakan $20 \times 20$ $\mathrm{cm}$;

e) Pemeliharaan yang dilakukan yaitu penyiraman 2 kali sehari (pagi dan sore) disesuaikan dengan kondisi tanah. Penyiangan gulma dilakukan 3 kali di sesuaikan dengan kondisi lahan. Penyulaman bibit dilakukan 7 hari setelah tanam, agar tanaman pada petak percontohan tidak terlalu jauh perbedaan umurnya. Kegiatan pemupukan susulan dilakukan 7 hari dan 20 hari setelah tanam. Takaran pupuk yang di gunakan $10 \mathrm{gr}$ per lubang tanam atau setara dengan 1 genggam tangan.

f) Setelah berumur 30 hari selada pada petak percontohan siap di panen.

5) Pengamatan

Data yang dikumpulkan pada petak percontohan dengan melakukan pengamatan setiap minggu yaitu tinggi tanaman dan jumlah daun. Sampel yang digunakan diambil secara acak yang dapat mewakili semua populasi kegiatan budidaya. Banyak sampel setiap perlakuan diambil 72 tanaman untuk dijadikan sebagai pengamatan. Analisis yang digunakan dari kegiatan petak percontohan yaitu menggunakan data hasil pengamatan mingguan dan analisis uji-t untuk melihat signifikansi perbedaan penggunaan pupuk kascing dengan pupuk kotoran ayam yang biasa petani gunakan, sebagai berikut:

a) Tinggi Tanaman

Berdasarkan data yang diperoleh dari hasil pengamatan setiap minggu pada pertumbuhan tinggi tanaman dilakukan 4 kali pengamatan. Pengukuran dilakukan dari permukaan tanah sampai daun tertinggi.

b) Daun Tanaman

Berdasarkan data yang diperoleh dari hasil pengamatan setiap minggu pada pertumbuhan tanaman dengan menghitung jumlah daun dilakukan 4 kali pengamatan. Pengamatan dilakukan dengan menghitung jumlah daun yang telah terbuka, selama kegiatan budidaya.

Biaya untuk kegiatan petak percontohan dapat dilihat pada Tabel 1. 
Tabel 1. Biaya Petak Percontohan

\begin{tabular}{|c|c|c|c|}
\hline Faktor Produksi & Jumlah Satuan & Harga Satuan & Jumlah \\
\hline \multicolumn{4}{|c|}{ Biaya Variabel } \\
\hline Benih & 1 bungkus & $25.000,-$ & $25.000,-$ \\
\hline Pupuk Ayam & 1 karung & $15.000,-$ & $15.000,-$ \\
\hline Cacing & $2 \mathrm{~kg}$ & 15.000,- & $30.000,-$ \\
\hline \multicolumn{3}{|c|}{ Jumlah Total } & $55.000,-$ \\
\hline \multicolumn{4}{|c|}{ Biaya Tetap } \\
\hline Mulsa & 30 meter & $4.000,-$ & $120.000,-$ \\
\hline Bambu & 3 bambu & $5.000,-$ & 15.000,- \\
\hline Cangkul & 1 buah & $50.000,-$ & $50.000,-$ \\
\hline Keranjang Kayu & 2 buah & $30.000,-$ & $60.000,-$ \\
\hline Skop & 1 buah & $15.000,-$ & $15.000,-$ \\
\hline Timbangan & 1 buah & $65.000,-$ & $65.000,-$ \\
\hline \multicolumn{3}{|c|}{ Jumlah Total } & 325.000,- \\
\hline
\end{tabular}

\section{HASIL DAN PEMBAHASAN}

Kegiatan budidaya pada petak percontohan hanya tumbuh $80 \%$. Hal ini disebabkan karena penggunaan kascing yang baru pada lahan, lubang tanam pada petak percontohan penggunaan pupuk kotoran ayam terdapat sarang semut sehingga tanaman tidak tumbuh dan pelaksanaan penyulaman tidak dilakukan kembali karena jangka waktu tanam terlalu jauh dengan tanam pertama.

Kebutuhan pupuk yang diperlukan selama kegiatan petak percontohan yaitu dengan melakukan kegiatan pembuatan pupuk kascing melalui pemanfaatan limbah kotoran sapi. Kecamatan Sukalarang memiliki peternak sapi yang cukup banyak, namun pemanfaatan limbah kurang diperhatikan. Adanya pembuatan petak percontohan ini, maka limbah kotoran sapi yang terbengkalai dapat dimanfaatkan dan kegiatan pembuatan pupuk kascing tidak terkendala dalam mencari pakan cacing dan sudah tersedia secara gratis.

Pengamatan yang dilakukan pada petak percontohan sejalan dengan pengkajian Putra et al. (2016), bahwa pengamatan penggunaan pupuk organik pada tanaman selada dapat melalui pengamatan tinggi tanaman dan jumlah daun, untuk mengetahui perbedaan pada budidaya selada menggunakan pupuk kascing dengan pupuk kotoran ayam. Hasil pengamatan yang diperoleh yaitu:

\section{Tinggi Tanaman}

Berdasarkan data yang diperoleh dari hasil pengamatan setiap minggu pada pertumbuhan tinggi tanaman dilakukan 4 kali pengamatan. Hasil pengamatan rata-rata pertumbuhan 
tanaman selada setiap minggu dapat dilihat pada Tabel 2.

Tabel 2 Hasil pengamatan tinggi tanaman dan jumlah daun

\begin{tabular}{lcccc}
\hline Amatan & \multicolumn{2}{c}{ Tinggi tanaman (cm) } & \multicolumn{2}{c}{ Jumlah daun (helai) } \\
\cline { 2 - 5 } & $\begin{array}{c}\text { Pupuk kotoran } \\
\text { ayam }\end{array}$ & Pupuk kascing & $\begin{array}{c}\text { Popok kotoran } \\
\text { ayam }\end{array}$ & Pupuk kascing \\
\hline 1 & 5,73 & 5,72 & 4,34 & 4,35 \\
2 & 9,43 & 9,74 & 5,6 & 5,54 \\
3 & 14,78 & 14,78 & 7,44 & 7,44 \\
4 & 21,51 & 21,5 & 8,97 & 8,99 \\
\hline
\end{tabular}

Hasil pengamatan pada Tabel 2 menunjukkan bahwa pertumbuhan tinggi tanaman tidak mengalami perbedaan yang nyata antara tanaman menggunakan pupuk kascing dengan tanaman menggunakan pupuk kotoran ayam. Data yang diperoleh selanjutnya dianalisis untuk mengetahui perbedaan pertumbuhan tinggi tanaman menggunakan uji-t sampel bebas (Independent sampel $t$ test), menggunakan program Microsoft excel dan Software Statistical Product and Service Solution (SPSS).

Hasil analisis uji-t nilai signifikansinya 0,441 maka tidak terdapat perbedaan yang signifikan antara penggunaan pupuk kascing dengan pupuk kotoran ayam pada budidaya selada.

\section{Daun Tanaman}

Data diperoleh dari hasil pengamatan terhadap jumlah daun selama 4 kali pengamatan juga dapat dilihat pada Tabel 2.
Tabel 2 menunjukkan bahwa pertumbuhan jumlah daun tanaman tidak mengalami perbedaan yang nyata antara tanaman menggunakan pupuk kascing dengan tanaman menggunakan pupuk kotoran ayam. Analisis uji-t sampel bebas (Independent sampel $t$ test) dengan program Microsoft excel dan Software Statistical Product and Service Solution (SPSS).

Berdasarkan hasil uji-t menunjukkan nilai signifikansi $t$ sebesar 0,441, artinya tidak terdapat perbedaan yang signifikan antara penggunaan pupuk kascing dengan pupuk kotoran ayam pada budidaya selada.

Hasil penelitian di atas berbeda dengan hasil Kartini (2015), yang menyatakan penggunaan kascing memiliki pengaruh nyata terhadap produksi yang diperoleh. Ada beberapa kemungkinan mengapa hasil pada petak percontohan ini tidak berbeda nyata. Penggunaan pupuk 
organik pada kegiatan budidaya tidak bisa langsung terlihat manfaatnya serta respon tanaman yang lambat, karena menerima pupuk yang jenis baru. Selain itu penggunaan jenis bibit yang digunakan mempengaruhi lambatnya respon tanaman terhadap penggunaan pupuk (Hartatik, 2015).

Hasil panen pada petak percontohan dibagi menjadi 2 , yaitu panen pada petak penggunaan kotoran ayam dan pada petak penggunaan pupuk kascing. Produksi yang diperoleh dari petak percontohan menggunakan kascing 55 ikat dan pada petak percontohan menggunakan kotoran ayam sebanyak 50 ikat. Setiap satu ikat terdiri dari 4-6 tanaman, disesuaikan dengan ukuran penjualan perikat. Harga selada perikat sebesar Rp. 5.000/ikat, di mana penjualan diantar ke tempat pembeli.

Perolehan hasil panen dari petak percontohan menggunakan kascing sebesar Rp. 275.000,- dan pada petak percontohan menggunakan pupuk kotoran ayam sebesar Rp. 250.000,-Perbedaan hasil produksi tidak terlalu jauh, karena penggunaan pupuk kascing masih tahap baru dan manfaat yang diperoleh tidak langsung sangat terlihat. Maka pada kegiatan budidaya selada pada petak percontohan memperoleh hasil sebesar Rp. 525.000,- dengan pengeluaran sebesar Rp. 380.000,- jadi terdapat keuntungan yang diperoleh sebesar Rp. $145.000,-$.

\section{SIMPULAN DAN SARAN}

\section{Simpulan}

Tinggi tanaman, jumlah daun dan produksi selada yang menggunakan pupuk kascing tidak berbeda nyata dengan yang menggunakan pupuk dari kotoran ayam.

\section{Saran}

Saran dari penelitian ini adalah sebagai berikut:

1. Pupuk kascing dapat digunakan dalam budidaya selada

2. Petani perlu dimotivasi untuk dapat memantaafkan limbah kotoran sapi sebagai media pembuatan kascing

\section{DAFTAR PUSTAKA}

BPSI [Badan Pusat Statistik Indonesia]. 2014. Indonesia dalam angka 2014. Badan Pusat Statistik Indonesia.

Putra DP, Handajaningsih M, Riwandi R. 2016. Pertumbuhan dan Hasil Tanaman Selada pada Tiga Jenis Tanah Mineral dengan Pemberian Dosis Pupuk 
Kandang Sapi yang Berbeda.

Akta Agrosia. Volume 19 (4):

104-111.

Nugroho DB, Maghfour MD, Herlina N.

2017. Pertumbuhan dan Hasil

Tanaman Selada (Lactuca sativa

L.) Akibat Pemberian Biourin

Sapi dan Kascing. Jurnal

Produksi Tanaman. Volume 5

(4): 600-607.

Kartini. 2015. Pengaruh Dosis Pupuk

Kascing terhadap Hasil Tanaman

Sawi (Brassica juncea L.) Sifat

kimia dan Boilogi pada Tanah

Inceptisol Klungkung. Jurnal

Agroekoteknologi Tropika.

Volume 4 (3): 2301-6515.

Hartatik. 2015. Peran Pupuk Organik dalam Peningkatan Produktivitas Tanah dan Tanaman. Jurnal

Sumberdaya Lahan. Volume 9

(2): 107-120. 